\title{
A Preliminary in vitro Study to Evaluate Poly-3-Hydroxy Butyrate as an Anticoccidial Agent against Oocysts of E. tenella
}

\author{
T. Aadithya ${ }^{1}$, S. Meignanalakshmi ${ }^{1}$, M. Raman ${ }^{2}$, M. Parthiban ${ }^{1}$ and K. Vijayarani ${ }^{1}$ \\ ${ }^{1}$ Department of Animal Biotechnology, Madras Veterinary College, TANUVAS, \\ Chennai-7, India \\ ${ }^{2}$ Translational Research Platform for Veterinary Biologicals, MadhavaramMilk Colony, \\ TANUVAS, Chennai-51, India
}

*Corresponding author

\section{A B S T R A C T}

Keywords

Coccidiosis, Sporulation inhibition, TEM and SEM analysis, E. tenella oocyst, PHB

Article Info

Accepted: 26 July 2018 Available Online: 10 August 2018
The present study was conducted to evaluate the effect of Poly-3-Hydroxy butyrate against the sporulation of oocyst of E. tenella. In this study four different doses of PHB which was extracted from the Bacillus subtilis culture, 10,20 , 50and $100 \mathrm{mg}$ were used with $2.5 \%$ potassium dichromate as positive control and distilled water as negative control. The experiment was carried out in 24 well plates. The sporulation efficiency was evaluated by counting the sporulated and unsporulated oocysts using haemocytometer and percentage efficiency of sporulation inhibition was calculated. Data were analysed using chi square test. The PHB at $100 \mathrm{mg}$ concentration showed significant effect on sporulation inhibition when compared to other doses of PHB and positive control.

\section{Introduction}

Coccidiosis is the major parasitic disease which causes serious threat to the poultry industry. It is caused by the Apicomplexan protozoa called as Eimeria which consists of many species which affects the poultry either individually or in combination. Severe outbreaks resulted in tremendous economic loss due to increased morbidity and mortality. The genus Eimeria most commonly affects the intestinal tract, thereby affects the intestinal epithelium which inturn leads to reduced feed efficiency and body weight gain (Min et al., 2004; Dalloul and Lillehoj, 2005). The most common species of Eimeria which affects poultry industry was E. tenella, E. acervulina and E. maxima. Coccidiosis is mainly caused by the ingestion of sporulated oocysts which will be able to survive in the environment for several months. This disease is mainly controlled by the use of some chemotherapeutic agents and some anticoccidial chemicals. Due to extensive and 
indiscriminate use of anticoccidial drugs in poultry industry leads to the development of drug resistance against all the drugs. Despite the global acceptance and success of these drugs in controlling avian coccidiosis, the poultry industry is under constant pressure to reduce the dependence on anticoccidial drugs (Williams, 1999). These problem become public health concern about the presence of drug residues in poultry products which made the industry to look for the alternatives. Although various natural products were used for controlling coccidiosis, still none of the studies were repeated and not led to large scale applications of any of these compounds in practice. Inspite of all these drawbacks, associated with control strategies still there is need for alternatives. Poly-3-Hydroxy Butyrate which is a biopolymer produced by various groups of bacteria, a neutraceutical compound which was used as a feed additive as well as it suppress or inhibit the pathogenic bacteria in GI (Gastro intestinal) tract such as E.coli, Vibrio, Salmonella and it also has antimicrobial activity (Singh and Parmar, 2011). The attractive features such as Biocompatibility, biodegradability and non toxicity which renewed the interest of using this as an alternative source. Hence in the present study PHB (Poly-3-hydroxy butyrate) was evaluated for its effect against $E$. tenella oocyst in terms of sporulation inhibition and cell wall integrity (Fig. 1).

\section{Materials and Method}

\section{Collection of faecal sample for recovery of oocyst}

Fresh faecal droppings were collected from Translational Research Platform in Veterinary Biologicals animal shed, Madhavaram Milk Colony, Chennai-51. About 50-100g of fresh faecal sample was collected from the $E$. tenella oocyst challenged birds.

\section{Processing of faecal sample}

The faecal sample of about 25-30 grams were weighed and mixed with $75-100 \mathrm{ml}$ of distilled water. The suspension was mixed thoroughly and stained using double layer of nylon sieve with pore size approximately $1 \mathrm{~mm}$ and filtrate was transferred into $50 \mathrm{ml}$ Falcon tubes (Tarson, India) and centrifuged at $3000 \mathrm{rpm}$ for 10mins. The supernatant was discarded after centrifugation and saturated salt solution was added to the pellet and left for few minutes for the oocyst to reach the top and $5 \mathrm{ml}$ of the supernatant was taken in a new $50 \mathrm{ml}$ tube and $30 \mathrm{ml}$ of distilled water was added and centrifuged at $3000 \mathrm{rpm}$ for $10 \mathrm{~min}$. The above step was repeated 3-5 times to remove all the salt solution. Final pellet was mixed with water and the oocyst count were eneumerated using McMaster counting chamber (Long et al., 1986).

\section{Extraction of PHB from Bacillus spp}

\section{Preparation of NDMM medium}

For the production of PHB by Bacillus spp NDMM medium was used. The NDMM Medium was prepared by using the following constituents such as Dextrose (5g), Sodium chloride (0.05g), Magnesium sulphate $(0.05 \mathrm{~g})$, Potassium dihydrogen phosphate $(0.125 \mathrm{~g})$, Peptone $(1.25 \mathrm{~g})$, Yeast extract $(1.25 \mathrm{~g})$ and distilled water $(500 \mathrm{ml})$ (Panigrahi and Badveli, 2013).

The medium was prepared for $2500 \mathrm{ml}$ and was autoclaved at $121^{\circ} \mathrm{C}$ for 20 mins at $15 \mathrm{lbs}$ pressure to avoid contamination. After autoclaving, Bacillus spp culture was added into the medium at the rate of $25 \mathrm{ml}$ per $500 \mathrm{ml}$ of medium.

Large scale production of PHB from Bacillus spp was carried out using Bioreactor. 


\section{Extraction of PHB from NDMM medium}

PHB was extracted using the dispersion method of sodium hypochlorite and chloroform (Singh and Parmar, 2011) with minor modifications.

In vitro anticoccidial activity of PHB against oocyst of $E$. tenella

The oocyst of E. tenella collected from fresh faecal sample was used for in vitro study. In vitro evaluation was performed as per the protocol described by (Mikail et al., 2016). In vitro evaluation was performed in 24 well plates to study the sporulation inhibition efficiency of the compound.

The study was conducted using PHB at different doses 10mg, 20mg, 50mg and $100 \mathrm{mg}$ and Amprolium $1 \mathrm{mg}$ (anticoccidiostat), 2.5\% potassium dichromate was taken as positive control and oocyst suspension as negative control.

The sporulated and unsporulatedoocyst were counted at 0,24 and 48 hours using haemocytometer. Each treatment contains $\leq 50,000$ oocyst.

Evaluation of PHB against cell wall integrity of oocyst

Four doses of PHB were taken 10, 20, 50 and $100 \mathrm{mg}$ with amprolium as positive control and $2.5 \%$ potassium dichromate as negative control. Amprolium was taken at the rate of $1 \mathrm{~g} / \mathrm{ml}$. Approximately $10 \mu 1$ of sample was taken and diluted with water and added to 24 well plates with different doses of PHB, positive and negative control.

All the samples were maintained at room temperature and observed for lysis of cell wall after 48 hours. The cell wall integrity was assessed by subjecting the sample to SEM and
TEM analysis.

Transmission Electron Microscope (TEM) analysis of PHB $(100 \mathrm{mg})$ treated $E$. tenellaoocyst

TEM analysis was carried out at Centralised Instrumentation Laboratory, Madras Veterinary College, Chennai-7. A drop of PHB treated oocyst suspension was pipetted onto the specimen plug for Transmission Electron Microscope. The mounted specimens were placed in an incubator and allowed to dry. The plug containing PHB (100mg) treated oocyst was examined by Transmission Electron Microscope. Photographs were made with a polaroid camera.

Scanning Electron Microscope (SEM) analysis of $P H B(100 \mathrm{mg})$ treated $E$. tenellaoocyst

SEM analysis of PHB (100mg) treated $E$. tenella oocyst was carried out at the Department of Mechanical Engineering, Anna University, Guindy. A drop of PHB (100mg) treated oocyst suspension was pipetted onto a specimen plug for the scanning electron microscope, and allowed to air dry. Mounted specimens were placed in. a vacuum evaporator and coated with a layer of gold, $100 \AA$ thick. The plug containing coated oocysts was placed in a Japanese Scanning Microscope (JSM-2) and examined. Photographs were made with a polaroid camera.

\section{Statistical analysis}

Both sporulated and unsporulated oocyst was counted and sporulation inhibiting percentage at 0,24 and 48 hours were, calculated, tabulated and statistical analysis was carried out. The data were analysed by one way ANOVA.

\section{Results and Discussion}


Different doses of PHB showed dose dependent inhibition for the sporulation of $E$. tenella oocysts as compared to the control group (2.5\% Potassium dichromate). The statistical analysis showed that the doe of 100mg PHB inhibits the sporulation to certain extent followed by $50 \mathrm{mg}$ of PHB.

Different doses of PHB showed dose dependent inhibition of sporulation of $E$. tenella oocysts as compared to Positive control groups $\left(\mathrm{K}_{2} \mathrm{Cr}_{2} \mathrm{O}_{7}\right)$ and negative control group (Oocyst suspension). It can be seen from the Table 1a-1d $91.4 \%$ of oocysts of $E$. tenella managed to sporulate in the control incubations containing $\mathrm{K}_{2} \mathrm{Cr}_{2} \mathrm{O}_{7}$ (Positive control) and oocyst suspension (Negative Control) whereas in incubation containing 10 , 20, 50 and $100 \mathrm{mg}$ of PHB $86 \%, 81 \%, 74 \%$ and $68 \%$ of the oocyst were able to sporulate at $48 \mathrm{hrs}$. The maximum sporulation of Eimeria spp differs between the species. The different dose of PHB showed maximum inhibition at $100 \mathrm{mg}$ followed by $50 \mathrm{mg}, 20 \mathrm{mg}$ and $10 \mathrm{mg}$ respectively when compared to control groups. The sporulation inhibition of E. tenella oocyst treated with PHB at 0,24 and $48 \mathrm{hrs}$ is given in the Table $1 \mathrm{~d}$.

\section{Transmission Electron Microscopic analysis of PHB $(100 \mathrm{mg})$ treated E. tenella oocyst}

E. tenella oocyst treated with $100 \mathrm{mg}$ of PHB analysed by TEM (Fig. 2) revealed shrinkage in the proteinaceous layer of micropylar area.

Scanning Electron Microscope analysis of PHB treated E. tenella oocyst

SEM analysis of PHB treated E. tenella oocyst showed Breakage at the outer proteinaceous wall of oocyst is shown in the Figure 3.

Table.1a The effect of PHB on sporulation inhibition of E. tenella oocyst at 0 hours

\begin{tabular}{|c|c|c|c|c|}
\hline $\begin{array}{l}\text { Dose of the } \\
\text { compound }\end{array}$ & $\begin{array}{l}\text { Sporulated oocysts } \\
(n=6)(\text { Mean } \pm \text { SD })\end{array}$ & $\begin{array}{l}\text { Unsporulated } \\
\text { oocysts }(n=6) \text { (Mean } \\
\pm \text { SD) }\end{array}$ & $\begin{array}{l}\text { Percentage of } \\
\text { unsporulated oocysts }\end{array}$ & $\begin{array}{l}\text { Percentage of } \\
\text { sporulated oocysts }\end{array}$ \\
\hline PHB(10mg) & $2666 \pm 1032$ & $47000 \pm 2097$ & 94.63 & 5.37 \\
\hline PHB(20mg) & $2666 \pm 1032$ & $47666.66 \pm 1505$ & 94.70 & 5.30 \\
\hline PHB(50mg) & $2333 \pm 816$ & $48333 \pm 1505$ & 95.39 & 4.61 \\
\hline PHB(100mg) & $2333 \pm 816$ & $46666 \pm 1632$ & 95.20 & 4.8 \\
\hline Amprolium(1mg) & $2333 \pm 816$ & $47333 \pm 2065$ & 95.30 & 4.70 \\
\hline Positive control & $2333 \pm 816$ & $48333 \pm 1505$ & 95.39 & 4.61 \\
\hline Negative control & $2333 \pm 816$ & $48333 \pm 1505$ & 95.39 & 4.61 \\
\hline
\end{tabular}

Positive Control- 2.5\% Potassium Dichromate. Negative control- Oocyst suspension. Each treatment contains $\leq$ 50,000 oocyst 
Table.1b The effect of PHB on sporulation inhibition of E. tenella oocyst at 24 hours

\begin{tabular}{|c|c|c|c|c|c|c|}
\hline 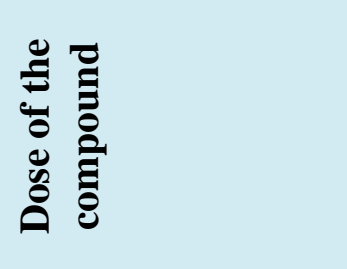 & 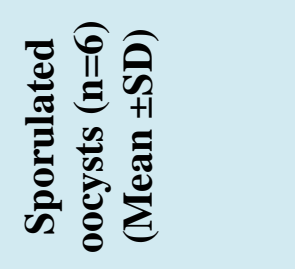 & 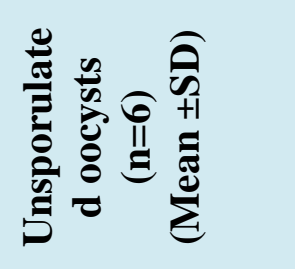 & 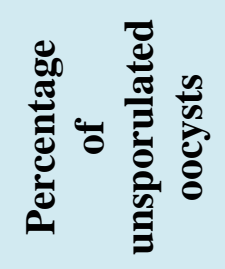 & 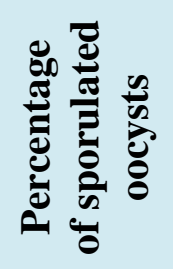 & 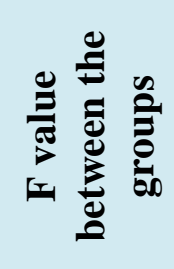 & 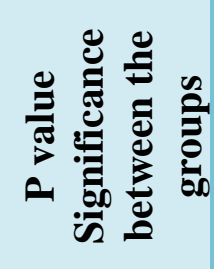 \\
\hline PHB(10mg) & $26000 \pm 1786$ & $22333.83 \pm 1505$ & 46.20 & 53.80 & \multirow{7}{*}{53.998} & \multirow{7}{*}{$.000 * *$} \\
\hline PHB(20mg) & $28666 \pm 1632$ & $22000 \pm 1264$ & 45.42 & 54.58 & & \\
\hline PHB(50mg) & $23333 \pm 1632$ & $26666 \pm 1032$ & 53.33 & 46.67 & & \\
\hline PHB(100mg) & $19000 \pm 1095$ & $31666.66 \pm 1505$ & 62.40 & 37.60 & & \\
\hline Amprolium (1mg) & $27333.33 \pm 1032$ & $23000 \pm 2097$ & 54.30 & 37.60 & & \\
\hline Positive control & $46000 \pm 1264$ & $4333.33 \pm 1505$ & 8.60 & 91.40 & & \\
\hline Negative control & $35000 \pm 2097$ & $14333.33 \pm 1505$ & 29.05 & 70.95 & & \\
\hline
\end{tabular}

Positive Control- 2.5\% Potassium Dichromate. Negative control- Oocyst suspension. Each treatment contains $\leq$ 50,000 oocyst.

** Indicates highly significant. ${ }^{* *} \mathrm{P} \leq 0.001$ between the groups indicates highly significant.

Table.1c The effect of PHB on sporulation inhibition of E. tenella oocyst at 48

Hours

\begin{tabular}{|c|c|c|c|c|}
\hline $\begin{array}{l}\text { Dose of the } \\
\text { compound }\end{array}$ & $\begin{array}{l}\text { Sporulated oocysts } \\
(n=6)(\text { Mean } \pm \text { SD })\end{array}$ & $\begin{array}{l}\text { Unsporulated } \\
\text { oocysts } \quad(n=6) \\
(\text { Mean } \pm \text { SD })\end{array}$ & $\begin{array}{l}\text { Percentage of } \\
\text { unsporulated } \\
\text { oocysts }\end{array}$ & $\begin{array}{l}\text { Percentage } \\
\text { of } \\
\text { sporulated } \\
\text { oocysts }\end{array}$ \\
\hline PHB(10mg) & $43333 \pm 1032$ & $7000 \pm 1095$ & 13.90 & 86.10 \\
\hline PHB(20mg) & $39666 \pm 1505$ & $9333 \pm 1032$ & 19.00 & 81.00 \\
\hline PHB(50mg) & $37666 \pm 1505$ & $13000 \pm 2756$ & 25.65 & 74.35 \\
\hline PHB(100mg) & $33000 \pm 2097$ & $15333 \pm 1632$ & 31.70 & 68.30 \\
\hline Amprolium(1mg) & $36000 \pm 1786$ & $13666 \pm 2943$ & 27.51 & 72.49 \\
\hline Positive control & $46000 \pm 1264$ & $4333 \pm 1505$ & 8.60 & 91.40 \\
\hline Negative control & $42000 \pm 1264$ & $8333 \pm 1505$ & 16.56 & 83.44 \\
\hline $\begin{array}{l}\text { F value between the } \\
\text { treatments }\end{array}$ & \multicolumn{4}{|l|}{134.813} \\
\hline $\begin{array}{l}\text { P value Significance } \\
\text { between the groups }\end{array}$ & \multicolumn{4}{|l|}{$.000 * *$} \\
\hline
\end{tabular}

Positive Control- 2.5\% Potassium Dichromate. Negative control- Oocyst suspension. Each treatment contains $\leq$ 50,000 oocyst.

** Indicates highly significant.

** $\mathrm{P} \leq 0.001$ between the groups indicates highly significant. 
Table.1d The effect of PHB on sporulation of E.tenella oocysts at 0, 24 and 48 hours

\begin{tabular}{|c|c|c|c|}
\hline $\begin{array}{l}\text { Dose of the } \\
\text { compound }\end{array}$ & $\begin{array}{ll}\text { Percentage } & \text { of } \\
\text { sporulation } & \\
\text { inhibition } & \text { at } \\
\text { "'0"' hours } & \end{array}$ & $\begin{array}{ll}\text { Percentage } & \text { of } \\
\text { sporulation } & \\
\text { inhibition } & \text { at } \\
\text { ' } 24 \text { '' hours } & \end{array}$ & $\begin{array}{ll}\text { Percentage } & \text { of } \\
\text { sporulation } & \\
\text { inhibition } & \text { at } \\
\text { ' } 48 \text { ', hours } & \end{array}$ \\
\hline PHB(10mg) & 94.63 & 46.20 & 13.90 \\
\hline PHB(20mg) & 94.70 & 45.42 & 19.00 \\
\hline PHB(50mg) & 95.39 & 53.33 & 25.65 \\
\hline PHB(100mg) & 95.20 & 62.40 & 31.70 \\
\hline Amprolium(1mg) & 95.30 & 54.30 & 27.51 \\
\hline Positive control & 95.39 & 29.05 & 8.60 \\
\hline Negative control & 95.39 & 29.05 & 8.60 \\
\hline
\end{tabular}

Positive Control- 2.5\% Potassium Dichromate. Negative control- Oocyst suspension. Each treatment contains $\leq$ 50,000 oocyst.

Figure.1 Photomicrograph of Sporulated and unsporulated oocyst of E. tenella (400X)

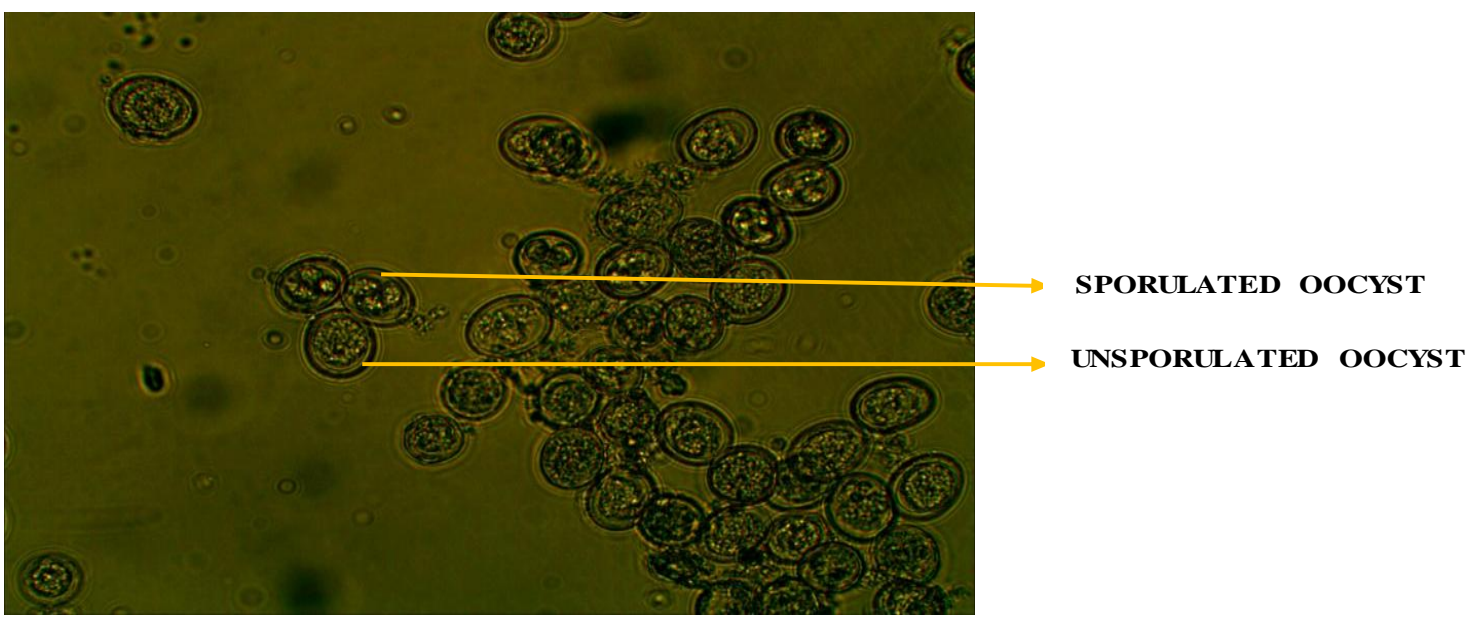

Figure.2 Transmission Electron Micrograph (TEM) of PHB (100mg) treated E. tenella oocyst at $48 \mathrm{hrs}$ at $3000 \mathrm{X}$

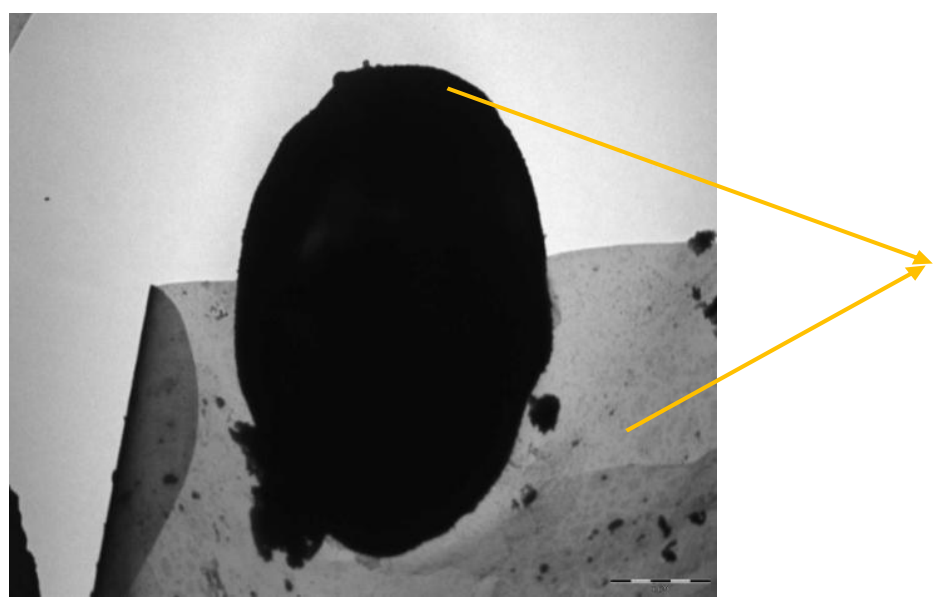

SHRINKAGE AND SMALL CIRCULAR DEPRESSION NOTICED IN THE OUTER PROTEINACEOUS

LA YER

MICROPYLAR

AREA 
Figure.3 Scanning Electron Micrograph (SEM) of PHB (100mg) 48hrs treated oocyst at 3000X

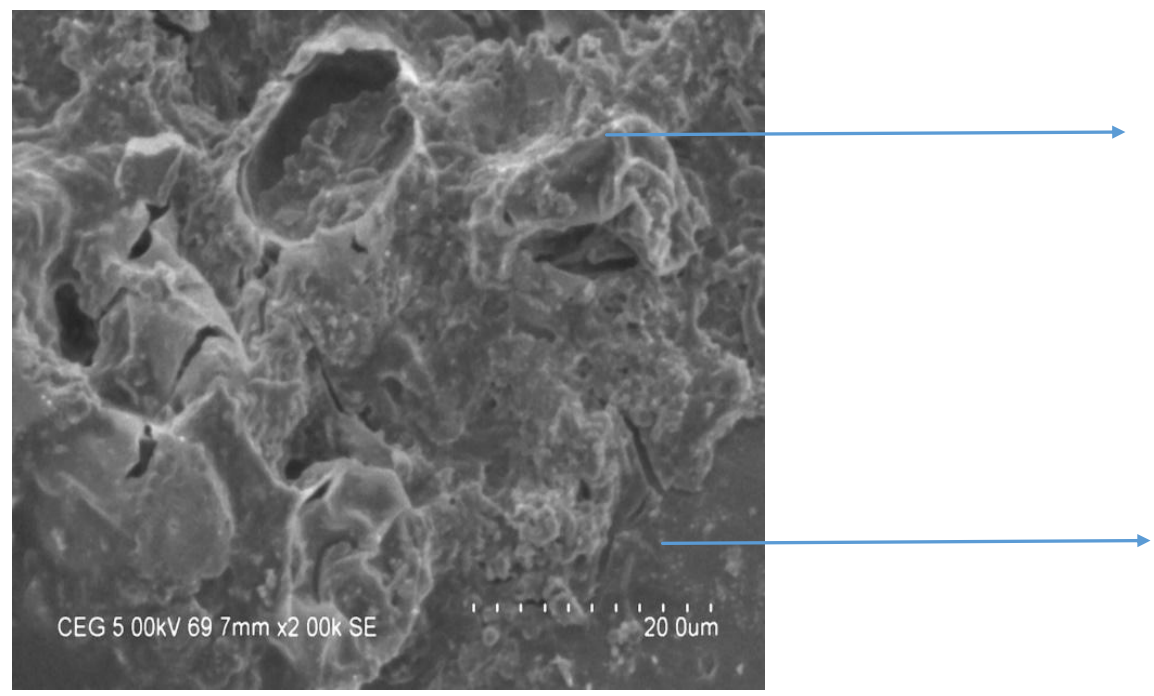

BREAKAGE OF OOCYST

OOCURS AT THE

MICROPYLAR LAYER

OF PROTEINACEOUS

WALL OF OOCYST

NORMAL OOCYST

WITHOUT ANY

DAMAGE

The drugs which can inhibit sporulation process are the best choice as preventive mechanisms against coccidiosis. Due to the lack of effective and non-toxic disinfectants against coccidian and recent restriction of coccidiostatic drugs in poultry production, lead to the search for safe and effective alternatives for controlling coccidiosis. Various studies have been carried out to study the sporulation inhibition by using various products. In the present study, the polymer PHB was used at different doses $(10,20,50$ and $100 \mathrm{mg}$ ) against the sporulation of $E$. tenella oocyst. The present study showed dose dependent inhibition of sporulation of $E$. tenella oocyst. At the dose rate of $100 \mathrm{mg}$ of PHB inhibited the sporulation at $62.40 \%$ followed by $50 \mathrm{mg}, 20 \mathrm{mg}$ and $10 \mathrm{mg}$ of PHB inhibited at $53.33 \%, 46.20 \%$ and $45.42 \%$ respectively, when compared to the Positive control and negative control, $8.60 \%$ and $29.05 \%$ respectively.

Hanan et al., (2009) conducted a trial using Xenorhabdus and Photorhabdus spp on sporulation of Eimeria oocyst and reported promising results for controlling the Eimeria in deep litter system. Remmal et al., (2013) used essential oil components against the chicken Eimeria oocyst and the number of oocyst decreased with $20 \mathrm{mg} / \mathrm{ml}$ of essential oil. In the present study the sporulation was inhibited at $100 \mathrm{mg}$ of PHB followed by $50 \mathrm{mg}, 20 \mathrm{mg}$ and $10 \mathrm{mg}$ of PHB when compared to control groups. Similar results were by Zaman et al., (2015). They performed an experiment using herbal extracts against Eimeria tenella oocyst and found out that these herbal extracts exhibited anti-sporulation effect by interfering in the physiological process necessary for sporulation. These extracts inhibited the sporulation at dose dependent manner from $500 \mu \mathrm{g}$ to $0.244 \mu \mathrm{g} / \mathrm{ml}$.

Jitviriyanon et al., (2016) used various essential oils collected from indigenous plants against the oocyst of E. tenella. Out of various oils, only two essential oils from $B$. pandurata and $O$. basilicum showed inhibition effect on sporulation of oocyst when compared with the positive control. By Comparing the present study with various studies of other products the PHB produced 
by Bacillus spp was shown to have sporulation inhibition effect.

Mikail et al., (2016) studied the anticoccidial activity of Methanolic extract of leaves of Lanneaschimperi against E. tenella oocyst. He studied the efficacy of these products against the cell wall of oocyst and found out that extracts at higher concentration $(100 \mathrm{mg})$ showed more efficacy on the lysis of cell wall of oocyst followed by $50 \mathrm{mg}$ and $25 \mathrm{mg}$ concentration when compared to the control groups. $100 \mathrm{mg}$ of extracts inhibited sporulation at $98 \%$ followed by $50 \mathrm{mg}$ and $25 \mathrm{mg}$ with sporulation inhibition at $89 \%$ and $68 \%$ respectively. The oocyst of coccidia are very resistant to physical and chemical treatment because of the presence of the two proteinaceous layers on its walls derived from the coalescence of wall forming bodies found in the macrogamete stage of parasite (Belli et al., 2006). The present study revealed that PHB could be used to break the oocyst which was more helpful in controlling as well as preventing coccidiosis which is causing major economic loss to the poultry industry.

PHB extracted from Bacillus spp inhibited the sporulation of E. tenella oocyst under invitro condition

\section{Conflict of interest}

None declared

\section{Acknowledgment}

The work designed was carried out for the award of M.V.Sc degree in Animal Biotechnology in the academic year 20162018. The author wishes to thank the Tamil Nadu Veterinary and Animal Sciences University for funding the entire research project and Department of Animal Biotechnology for providing all assistance with equipment and chemicals

\section{References}

Belli, S.I., N.C. Smith and Ferguson, D.J.P. 2006. The coccidian oocyst: a tough nut to crack. Trends parasitol22: 416-423.

Dalloul, R. Aand Lillehoj. H. S. 2005. Recent advances in immunomodulation and vaccination strategies against coccidiosis. Avian Dis. 49:1-8.

Hanan, A., E. Sadawy, M. Rabab, E. Khateeb and Kutkat, A.M. 2009. A Preliminary InVitro Trial on the Efficacy of Products of Xenorhabdus and Photorhabdus Spp. on Eimeria Oocyst. Glob. Vet.3(6): 489-494.

Jitviriyanon, S., P. Phanthong, P. Lomarat, N. Bunyapraphatsara, S. Porntrakulpipat and N. Paraks. 2016. In vitro study of anti-coccidial activity of essential oils from indigenous plants against Eimeria tenella. VetParasitol, 228: 96102.

Long, P. L., J. Johnson, M.E. McKenzie, E. Perry, M.S. Crane and Murray.P.K, 1986. Immunization of young broiler chickens with low level infections of Eimeria tenella, E. acervulina, or E. maxima. Avian Pathol.15:271-278.

Mikail, H.G., M. Yusuf and Hussain. G, 2016. In vitro Anticoccidial Activity of Methanolic Leaves Extract of Lanneaschimperi Against Oocysts of Eimeria tenella. J Pharm Biol Sci. 11(3): 35-38.

Min, W., R.A Dalloul and Lillehoj, H.S, 2004. Application of biotechnological tools for coccidian vaccine development. J. Vet. Sci. 5, 279-288.

Panigrahi, S and Badveli, U,2013. Screening, Isolation and Quantification of PHBProducing Soil Bacteria. Int J Eng Sci. 2(9):01-06.

Remmal, A., S. Achahbar, L. Bouddine, F. Chami and Chami, N, 2013. Oocysticidal Effect of Essential Oil 
Components against Chicken Eimeria Oocysts. Int J Vet Med. Research \& Reports, Article ID 599816, 8 pages

Singh, P and Parmar, N, 2011. Isolation and characterization of two novel polyhydroxybutyrate (PHB)-producing bacteria. AJB. 10(24): 4907-4919.

Williams, R. B., 1999. A compartmentalised model for the estimation of the cost of coccidiosis to the world's chicken production industry. Int. J. Parasitol. 29: 1209-1229.

Zaman, M.A., Z. Iqbal, R. Z. Abbas and Ehtisham-ul-Haque.S, 2015. In vitro Efficacy of Herbal Extracts against Eimeria tenella. Int. J. Agric. Biol. 17: 84-89.

\section{How to cite this article:}

Aadithya, T, S. Meignanalakshmi, M. Raman, M. Parthiban and Vijayarani, K. 2018. A Preliminary in vitro Study to Evaluate Poly-3-Hydroxy Butyrate as Anticoccidial Agent against Oocysts of E. tenella. Int.J.Curr.Microbiol.App.Sci. 7(08): 4364-4372. doi: https://doi.org/10.20546/ijcmas.2018.708.458 